\title{
Scalpel or Sheath? Outcomes Comparison Between Pre-Peritoneal Pelvic Packing and Angioembolization for Definitive Hemorrhage Control After REBOA
}

\author{
Megan Brenner MD MS ${ }^{1}$, Laura Moore MD², Bishoy Zakhary MPH ${ }^{1}$, \\ Alexander Schwed MD', Alexis Cralley MD', Anna Romagnoli MD', \\ Charles Fox MD ${ }^{5}$, Thomas Scalea MD ${ }^{4}$ and Clay Cothren Burlew MD $^{3}$ \\ 'Comparative Effectiveness and Clinical Outcomes Research Center, University of California Riverside/Riverside University Health \\ Systems, Riverside, CA, USA \\ ${ }^{2}$ Department of Surgery, University of Texas at Houston, Texas Trauma Institute, Houston, TX, USA \\ ${ }^{3}$ Department of Surgery, Denver Health Medical Center, Denver, CO, USA \\ ${ }^{4}$ Department of Surgery, University of Maryland Shock Trauma Center, Baltimore, MD, USA \\ ${ }^{5}$ Department of Surgery, University of Colorado, Denver, CO, USA
}

\begin{abstract}
Background: The role of angioembolization (AE) and pre-peritoneal pelvic packing (PPP) for pelvic hemorrhage control in the era of resuscitative endovascular balloon occlusion of the aorta (REBOA) has not been well described. Our aim was to investigate outcomes of PPP and AE after REBOA.

Methods: Patients who received aortic occlusion (AO) at Zone 3 (distal abdominal aorta) plus PPP and/or AE at three high-volume REBOA centers between February 2013 and December 2018 were identified. Outcomes were compared between three groups based on procedures performed: REBOA with PPP only (RPPP), REBOA with angioembolization only (RAE), and REBOA with PPP and AE (RPPPAE).

Results: Fifty-eight patients underwent REBOA at Zone 3; 37 RPPP, 13 RAE, 8 RPPPAE. Mean age was $45 \pm 16$ years, mean injury severity score (ISS) $35 \pm 13$, mean systolic blood pressure (SBP) pre-AO was $71 \pm 19 \mathrm{mmHg}$, and post-AO $\mathrm{SBP}$ was $110 \pm 34 \mathrm{mmHg}$. In-hospital mortality was $28 \%$, with the majority of deaths occurring in the intensive care unit. Age, ISS, admission SBP, physiology on admission and at the time of AO, response to AO, admission hemoglobin, blood products transfused, and rate of local wound infections were not different between RPPP and RAE groups. Comparing RPPP to RAE groups, duration of AO was significantly lower in the RPPP group ( $45+34$ vs $81+37$ mins, $p=0.012$ ), while rates of acute kidney injury (14\% vs $46 \%$ ) and distal embolism ( $8 \%$ vs $31 \%$ ) were higher in the RAE group ( $p=0.015,0.04$, respectively).There was no statistical difference in mortality between RPPP (22\%) and RAE patients (39\%), including on regression analysis controlling for duration of $A O$ and ongoing CPR at the time of AO. Conclusion: Despite a longer duration of $A O$ and higher rates of ongoing CPR at the time of AO in RAE patients, mortality rates are similar whether hemostasis is achieved after REBOA with pelvic packing or angioembolization. RPPP results in significantly lower systemic and local complication rates.
\end{abstract}

Keywords: REBOA; Pelvic Packing; Angioembolization

\section{Corresponding author:}

Megan Brenner MD MS, Professor of Surgery, University of California Riverside School of Medicine, Riverside University Health System, 26520 Cactus Ave CPC Suite 102-5, Moreno Valley CA 92555, USA.

Email: m.brenner@ruhealth.org
Presentation: This was presented as a poster presentation at the 78th Annual Meeting of the American Association of Surgery for Trauma (AAST) and Clinical Congress of Acute Care Surgery held in Dallas, Texas on September 18-21, 2019.

(C) 2020 CC BY 4.0 - in cooperation with Depts. of Cardiothoracic/ Vascular Surgery, General Surgery and Anesthesia, Örebro University Hospital and Örebro University, Sweden 


\section{INTRODUCTION}

Resuscitative endovascular balloon occlusion of the aorta (REBOA) has been adopted by many trauma centers as an adjunct in temporary control of pelvic fracture-related hemorrhage. Traditional options for hemorrhage control include product resuscitation, pelvic stabilization, reversal of coagulopathy, preperitoneal pelvic packing (PPP), and angioembolization (AE). REBOA has been added into algorithms of patients with pelvic hemorrhage [1,2]; however, little data exists to guide this practice. Where REBOA is utilized may also be determined by local factors such resource allocation and availability. REBOA, PPP, and AE can all be useful adjuncts in the setting of severe pelvic fracture hemorrhage. These techniques likely complement each other; however, institutional differences in practice have permitted the comparison between PPP and AE after REBOA in this study.

Our objective was to describe the characteristics and outcomes of patients who receive REBOA and additional procedures for pelvic fracture hemorrhage control.

\section{METHODS}

Patients who received aortic occlusion (AO) at Zone 3 (distal abdominal aorta) plus PPP and/or AE for isolated blunt pelvic fracture-related hemorrhage at 3 high-volume REBOA centers between February 2013 and December 2018 were identified. The three participating centers are high-volume REBOA centers known to have differing practice patterns for definitive hemorrhage control, but who all utilize REBOA as a temporizing measure for severe pelvic fracture hemorrhage refractory to initial resuscitation and/or pelvic stabilization. Data was collected prospectively into each center's database and the de-identified data was shared for analysis. Demographics, physiologic variables, and outcomes were reviewed from prospectively collected institutional registries. Inclusion criteria were patients older than 18 years of age who received REBOA on admission for pelvic-fracture related hemorrhage, then went on to additional procedures for hemostasis: PPP, AE, or both. Patients were divided into three groups based on hemostatic procedures performed: REBOA with PPP only (RPPP), REBOA with angioembolization only (RAE), and REBOA with PPP and AE (RPPPAE). The decision to perform REBOA was at the discretion of the attending physician according to each institution's algorithm, which follows the same indications for use of REBOA: a hypotensive patient with severe sub-diaphragmatic hemorrhage who has not responded to resuscitation. In this case, the hemorrhage was from severe blunt pelvic fracture.

Captured data included patient demographics, admission laboratory values and vital signs, Injury Severity Scores (ISS), and Abbreviated Injury Scale (AIS) scores. Physiologic data from admission until after AO was collected, as well as blood product utilization and procedural details. Outcomes such as hospital and intensive care unit (ICU) stay, ventilator days, discharge location, mortality, acute kidney injury (AKI), acute lung injury/acute respiratory distress syndrome (ALI/ARDS), distal embolism, pneumonia, sepsis or septic shock, hematoma, bacteremia, multi-organ dysfunction/multi-organ dysfunction syndrome (MODS), infections, local wounds, and need for amputation were also collected.

Univariate chi-squared analysis was performed between groups. Continuous variables were reported in mean \pm standard deviation while categorical variables were reported by count and their appropriate percentages. Binomial logistic regression was then performed controlling for covariates such as age, AO systolic blood pressure (SBP), and duration of AO with RPPP and RAE. Models were validated using the Hosmer-Lemeshow test.

\section{Ethical approval and informed consent}

Each institution received approval from their Institutional Review Board for this study including waiver of informed consent.

\section{RESULTS}

\section{Demographics}

During the study period, 58 patients undergoing REBOA for pelvic bleeding were identified: 37 RPPP, 13 RAE, and 8 RPPPAE (Table 1). Mean injury severity score (ISS) was $35 \pm 13$, and mean admission SBP was 96 $\mathrm{mmHg}$, while SBP at AO initiation was $72 \mathrm{mmHg}$, none of which differed between groups. Only $7.9 \%$ of patients had ongoing cardiopulmonary resuscitation at AO initiation: $5.4 \%$ of RPPP patients and $7.7 \%$ of RAE patients $(p=0.471)$. Mean time from admission to AO was not significantly different among the treatment groups (Table 1). Duration of AO was significantly different between RPPP and RAE groups (45 \pm 34.39 vs $81.01 \pm$ $37.21 \mathrm{~min}, p=0.012)$. In total, $52 \%$ of patients had a pelvic binder, and 59\% received pelvic external fixation. A total of 21 patients had both pelvic binders then subsequent external fixation $(36 \%)$. Mean blood products transfused within the first 24 hours were $17 \pm 16$ UPRBC, $13 \pm 12 \mathrm{FFP}, 8 \pm 10$ pack platelets. In total, 31 patients $(53.4 \%)$ received REBOA with the ER-REBOA catheter (Prytime Medical Inc, Boerne, TX).

\section{Outcomes and Complications}

In-hospital mortality was $28 \%$ and was not significantly different between groups (RPP 8 (21.6\%), RAE 5 $(38.5 \%)$, and RPPPAE $3(37.5 \%)$; Table 2$)$. The majority of deaths occurred in the intensive care unit and significantly more deaths occurred in the intensive care unit in the RAE group $(38.5 \%)$ than RPPP group $(5.4 \%)$ $(p=0.009$; Table 2$)$. Hospital stay, ICU stay, and ventilator days were also not significantly different between 
Table 1 Demographic and other baseline characteristics of REBOA and pre-peritoneal pelvic packing (RPPP), REBOA and angioembolization (RAE), and REBOA with both PPP and AE (RPPPAE).

\begin{tabular}{|c|c|c|c|c|c|}
\hline Baseline characteristics & $\begin{array}{c}\text { Total } \\
(n=58 ; 100 \%)\end{array}$ & $\begin{array}{c}R P P P \\
(n=37 ; 63.8 \%)\end{array}$ & $\begin{array}{c}R A E \\
(n=13 ; 22.4 \%)\end{array}$ & $\begin{array}{c}R P P P A E \\
(n=8 ; 13.8 \%)\end{array}$ & $\begin{array}{c}R P P \text { vs } R A E \\
\text { p value }\end{array}$ \\
\hline Age, mean $\pm S D$, years & $45.1 \pm 16.47$ & $43.89 \pm 15.17$ & $44.15 \pm 16.52$ & $52.25 \pm 22.17$ & 0.959 \\
\hline Gender & & & & & 0.828 \\
\hline Female, $n(\%)$ & $14(24.1)$ & $9(24.3)$ & $3(23.1)$ & $2(25.0)$ & \\
\hline Male, $n(\%)$ & $43(74.1)$ & $27(73.0)$ & $10(76.9)$ & $6(75.0)$ & \\
\hline Missing, $n(\%)$ & $1(1.7)$ & $1(2.7)$ & $0(0.0)$ & $0(0.0)$ & \\
\hline ISS, mean \pm SD & $35.78 \pm 10.67$ & $34.79 \pm 9.41$ & $39.09 \pm 13.14$ & $34.57 \pm 11.9$ & 0.259 \\
\hline Head AIS, mean \pm SD & $2.05 \pm 1.68$ & $1.92 \pm 1.68$ & $2.55 \pm 1.63$ & $1.67 \pm 1.86$ & 0.307 \\
\hline Chest AIS, mean \pm SD & $2.81 \pm 1.13$ & $3.05 \pm 0.83$ & $2.36 \pm 1.21$ & $2.83 \pm 1.72$ & 0.07 \\
\hline Abdomen AIS, mean \pm SD & $2.8 \pm 1.08$ & $2.75 \pm 1.03$ & $2.91 \pm 1.3$ & $2.83 \pm 0.8$ & 0.699 \\
\hline \multicolumn{6}{|l|}{ Admission vitals } \\
\hline $\mathrm{SBP}$, mean $\pm \mathrm{SD}, \mathrm{mmHg}$ & $95.53 \pm 33.07$ & $94.13 \pm 30.83$ & $93.92 \pm 38.28$ & $104.71 \pm 36.25$ & 0.985 \\
\hline $\mathrm{HR}$, mean $\pm \mathrm{SD}, \mathrm{bpm}$ & $115.7 \pm 32.1$ & $114.88 \pm 29.67$ & $127.58 \pm 30.06$ & $98.86 \pm 41.93$ & 0.214 \\
\hline $\mathrm{GCS}$, mean $\pm \mathrm{SD}$ & $10.65 \pm 5.17$ & $10.81 \pm 4.95$ & $9 \pm 5.85$ & $13 \pm 4.43$ & 0.297 \\
\hline $\mathrm{Hgb}$, mean $\pm \mathrm{SD}$ & $12.08 \pm 2.76$ & $12.26 \pm 2.89$ & $10.73 \pm 2.77$ & $12.86 \pm 1.76$ & 0.186 \\
\hline INR, mean \pm SD & $1.46 \pm 0.5$ & $1.49 \pm 0.49$ & $1.65 \pm 0.68$ & $1.15 \pm 0.05$ & 0.509 \\
\hline $\mathrm{pH}$, mean $\pm \mathrm{SD}$ & $7.23 \pm 0.16$ & $7.21 \pm 0.14$ & $7.3 \pm 0.29$ & $7.22 \pm 0.05$ & 0.246 \\
\hline Base deficit $[-]$, mean $\pm S D$ & $8.51 \pm 8.99$ & $8.65 \pm 9.96$ & $8.33 \pm 4.55$ & $8.07 \pm 8.55$ & 0.941 \\
\hline Lactate, mg/dl, mean \pm SD & $6.81 \pm 4.59$ & $6.99 \pm 4.96$ & $7.36 \pm 4.88$ & $5.5 \pm 2.22$ & 0.859 \\
\hline \multicolumn{6}{|l|}{$\mathrm{AO}$ initiation vitals } \\
\hline $\mathrm{SBP}$, mean $\pm \mathrm{SD}, \mathrm{mmHg}$ & $71.52 \pm 18.9$ & $68.3 \pm 17.8$ & $77 \pm 18.37$ & $76.71 \pm 23.34$ & 0.177 \\
\hline $\mathrm{HR}$, mean $\pm \mathrm{SD}, \mathrm{bpm}$ & $114.9 \pm 31.6$ & $113.44 \pm 35.35$ & $125.55 \pm 18.59$ & $103.57 \pm 32.59$ & 0.294 \\
\hline GCS, mean \pm SD & $6.02 \pm 4.86$ & $6.35 \pm 5.2$ & $4.54 \pm 3.31$ & $7.57 \pm 5.86$ & 0.262 \\
\hline \multicolumn{6}{|l|}{ Post Initial AO Vitals } \\
\hline $\mathrm{SBP}$, mean $\pm \mathrm{SD}, \mathrm{mmHg}$ & $110.4 \pm 34.3$ & $104.64 \pm 39.96$ & $124.33 \pm 22.83$ & $109.57 \pm 18.34$ & 0.12 \\
\hline $\mathrm{HR}$, mean $\pm \mathrm{SD}, \mathrm{bpm}$ & $102.2 \pm 36.9$ & $100.8 \pm 38.11$ & $109.33 \pm 40.79$ & $94.86 \pm 26.47$ & 0.537 \\
\hline GCS, mean \pm SD & $3.95 \pm 3.0$ & $4.12 \pm 3.56$ & $3.45 \pm 1.21$ & $4.14 \pm 3.02$ & 0.552 \\
\hline \multicolumn{6}{|l|}{ Change after $\mathrm{AO}$} \\
\hline Change in SBP, mean \pm SD, mmHg & $38.59 \pm 30.1$ & $35.58 \pm 31.25$ & $49.36 \pm 22.2$ & $32.86 \pm 36.05$ & 0.194 \\
\hline Change in $\mathrm{HR}$, mean $\pm \mathrm{SD}$ & $-13.4 \pm 32.6$ & $-13.5 \pm 35.28$ & $-16.09 \pm 34.76$ & $-8.71 \pm 21.93$ & 0.843 \\
\hline Change in GCS, mean \pm SD & $-1.83 \pm 4.24$ & $-2.04 \pm 4.56$ & $-0.36 \pm 1.21$ & $-3.43 \pm 5.86$ & 0.241 \\
\hline Lowest base deficit [-], mean \pm SD & $8.52 \pm 8.55$ & $9.36 \pm 9.47$ & $6.23 \pm 4.08$ & $7.54 \pm 8.45$ & 0.403 \\
\hline Highest INR, mean \pm SD & $1.63 \pm 0.51$ & $1.74 \pm 0.57$ & $1.43 \pm 0.19$ & $1.36 \pm 0.26$ & 0.172 \\
\hline Highest lactate, mean $\pm S D$, mg/dl & $8.27 \pm 5.03$ & $8.58 \pm 5.6$ & $7.77 \pm 3.58$ & $7.47 \pm 3.97$ & 0.72 \\
\hline Lowest Hgb, mean \pm SD & $8.73 \pm 1.84$ & $8.8 \pm 2.1$ & $8.9 \pm 1.02$ & $8.24 \pm 1.24$ & 0.903 \\
\hline Lowest $\mathrm{pH}$, mean \pm SD & $7.21 \pm 0.15$ & $7.18 \pm 0.12$ & $7.31 \pm 0.26$ & $7.23 \pm 0.03$ & 0.06 \\
\hline CPR at $\mathrm{AO}$ initiation, $n(\%)$ & $3(5.2)$ & $2(5.4)$ & $1(7.7)$ & $0(0)$ & 0.471 \\
\hline Time to initial $A O$, mean \pm SD & $34.67 \pm 36.1$ & $33.03 \pm 36.2$ & $48.3 \pm 44.3$ & $26.7 \pm 25.1$ & 0.519 \\
\hline Duration of initial $A O$, mean $\pm S D$, min & $60 \pm 39.93$ & $45 \pm 34.39$ & $81.01 \pm 37.21$ & $80 \pm 44.53$ & 0.012 \\
\hline$\leq 60 \min , n(\%)$ & $19(32.8)$ & $16(43.2)$ & $1(7.7)$ & $2(25.0)$ & 0.001 \\
\hline$>60 \min , n(\%)$ & $19(32.8)$ & $6(16.2)$ & $9(69.2)$ & $4(50.0)$ & \\
\hline Missing, $n(\%)$ & $20(34.5)$ & $15(40.5)$ & $3(23.1)$ & $2(25.0)$ & \\
\hline Final sheath diameter & & & & & 0.147 \\
\hline $7 \mathrm{Fr}, n(\%)$ & $31(53.4)$ & $23(62.2)$ & $4(30.8)$ & $4(50.0)$ & \\
\hline $11 / 12 \mathrm{Fr}, n(\%)$ & $14(24.1)$ & $8(21.6)$ & $3(23.1)$ & $3(37.5)$ & \\
\hline Other, $n(\%)$ & $2(3.4)$ & $1(2.7)$ & $1(7.7)$ & $0(0.0)$ & \\
\hline Missing, $n(\%)$ & $11(19.0)$ & $5(13.5)$ & $5(38.5)$ & $1(12.5)$ & \\
\hline Pelvic binder, $n(\%)$ & $27(51.9)$ & $18(51.4)$ & $5(55.6)$ & $4(50.0)$ & 0.969 \\
\hline Pelvic external fixation, $n(\%)$ & $34(58.6)$ & $22(59.5)$ & $8(61.5)$ & $4(50.0)$ & 0.895 \\
\hline TXA given, $n(\%)$ & $10(17.2)$ & $25(67.6)$ & $3(23.1)$ & $1(12.5)$ & 0.152 \\
\hline \multicolumn{6}{|l|}{ Resuscitation products } \\
\hline Packed red blood cells, mean \pm SD & $17.4 \pm 15.9$ & $17.58 \pm 16.47$ & $14.14 \pm 10.62$ & $19.86 \pm 18.84$ & 0.141 \\
\hline Fresh frozen plasma, mean \pm SD & $12.7 \pm 12.2$ & $12.58 \pm 13.04$ & $13.29 \pm 9.01$ & $12.86 \pm 12.59$ & 0.893 \\
\hline Platelets, mean \pm SD & $7.93 \pm 10.04$ & $10.11 \pm 11.62$ & $4 \pm 2.16$ & $3.14 \pm 3.24$ & 0.18 \\
\hline Cryoprecipitate, mean \pm SD & $1.27 \pm 1.96$ & $1.43 \pm 2.15$ & $1 \pm 1.53$ & $0.83 \pm 1.6$ & 0.624 \\
\hline Crystalloids, mean \pm SD & $4.98 \pm 4.21$ & $3.3 \pm 1.61$ & $9.72 \pm 7.4$ & $7.5 \pm 2.08$ & $<0.001$ \\
\hline
\end{tabular}

SD: standard deviation; bpm: beats per minute; GCS: Glasgow Coma Scale; Hgb: hemoglobin; HR: heart rate; INR: international normalized ratio; AlS: Abbreviated Injury Score; CPR: cardiopulmonary resuscitation. 
Table 2 Outcomes and complications of REBOA and pre-peritoneal pelvic packing (RPPP), REBOA and angioembolization (RAE), and REBOA with PPP and AE (RPPPAE) patients.

\begin{tabular}{|c|c|c|c|c|c|}
\hline Outcomes & $\begin{array}{c}\text { Total } \\
(n=58 ; 100 \%)\end{array}$ & $\begin{array}{c}R P P P \\
(n=37 ; 63.8 \%)\end{array}$ & $\begin{array}{c}R A E \\
(n=13 ; 22.4 \%)\end{array}$ & $\begin{array}{c}\text { RPPPAE } \\
(n=8 ; 13.8 \%)\end{array}$ & $\begin{array}{c}\text { RPP vs } R A E \\
p \text { value }\end{array}$ \\
\hline In hospital mortality, n (\%) & $16(27.6)$ & $8(21.6)$ & $5(38.5)$ & $3(37.5)$ & 0.285 \\
\hline ICU, n (\%) & $10(17.2)$ & $2(5.4)$ & $5(38.5)$ & $3(37.5)$ & 0.009 \\
\hline Operating room, $n(\%)$ & $6(10.3)$ & $6(16.2)$ & $0(0.0)$ & $0(0.0)$ & \\
\hline Hospital LOS, mean \pm SD, days & $27.96 \pm 25.2$ & $30.76 \pm 27.05$ & $19.54 \pm 18.02$ & $30.43 \pm 27.49$ & 0.176 \\
\hline ICU stay, $n(\%)$ & $47(81.0)$ & $28(75.7)$ & $12(92.3)$ & $7(87.5)$ & 0.371 \\
\hline ICU stay, mean \pm SD, days & $17.39 \pm 19.9$ & $15.371 \pm 19.6$ & $13.33 \pm 14.12$ & $18 \pm 17.64$ & 0.791 \\
\hline Ventilator use, $n(\%)$ & $47(81.0)$ & $29(78.4)$ & $11(84.6)$ & $7(87.5)$ & 0.780 \\
\hline Ventilator days, mean \pm SD, days & $12.9 \pm 16.59$ & $13.59 \pm 18.59$ & $9.36 \pm 11.17$ & $15.43 \pm 16.01$ & 0.710 \\
\hline Discharge GCS, mean \pm SD, days & $11.1 \pm 5.29$ & $11.73 \pm 4.85$ & $11 \pm 6$ & $9.4 \pm 6.07$ & 0.746 \\
\hline Discharge disposition & & & & & 0.022 \\
\hline Rehab/nursing facility, $n$ (\%) & $26(70.3)$ & $14(56.0)$ & $8(100.0)$ & $4(100.0)$ & \\
\hline Home, $n(\%)$ & $11(29.7)$ & $11(44.0)$ & $0(0.0)$ & $0(0.0)$ & \\
\hline Complications, $n(\%)$ & $28(48.3)$ & $14(37.8)$ & $9(69.2)$ & $5(62.5)$ & 0.051 \\
\hline Acute kidney injury, n (\%) & $16(27.6)$ & $5(13.5)$ & $6(46.2)$ & $5(62.5)$ & 0.015 \\
\hline ALI or ARDS, $n(\%)$ & $7(12.1)$ & $4(10.8)$ & $2(15.4)$ & $1(12.5)$ & 0.662 \\
\hline Distal embolism, $n$ (\%) & $7(12.1)$ & $3(8.1)$ & $4(30.8)$ & $0(0.0)$ & 0.043 \\
\hline Pneumonia, $n(\%)$ & $8(13.8)$ & $6(16.2)$ & $2(15.4)$ & $0(0.0)$ & 0.944 \\
\hline Sepsis or septic shock, $n(\%)$ & $5(8.6)$ & $3(8.1)$ & $2(15.4)$ & $0(0.0)$ & 0.452 \\
\hline Hematoma, $n(\%)$ & $3(5.2)$ & $1(2.7)$ & $2(15.4)$ & $0(0.0)$ & 0.098 \\
\hline Bacteremia, $n(\%)$ & $2(3.4)$ & $1(2.7)$ & $1(7.7)$ & $0(0.0)$ & 0.43 \\
\hline Multi-organ dysfunction/MODS, $n$ (\%) & $2(3.4)$ & $0(0.0)$ & $1(7.7)$ & $1(12.5)$ & 0.549 \\
\hline Infection requiring antibiotics, $n(\%)$ & $1(1.7)$ & $1(2.7)$ & $0(0.0)$ & $0(0.0)$ & 0.549 \\
\hline Infection requiring surgery, $n(\%)$ & $1(1.7)$ & $1(2.7)$ & $0(0.0)$ & $0(0.0)$ & 0.549 \\
\hline Local wound infection, $n(\%)$ & $1(1.7)$ & $1(2.7)$ & $0(0.0)$ & $0(0.0)$ & 0.549 \\
\hline Need for amputation, $n(\%)$ & $1(1.7)$ & $0(0.0)$ & $1(7.7)$ & $0(0.0)$ & 0.549 \\
\hline
\end{tabular}

LOS: length of stay; ALl: acute lung injury; ARDS: acute respiratory distress syndrome.

groups. Of those who survived to discharge, $44.8 \%$ of patients were transferred to rehab or nursing facilities, and of these $56.0 \%$ were RPPP patients and $100 \%$ were RAE patients $(p=0.02)$.

Systemic complications were more common within RAE patients than RPPP and RPPPAE groups. Rates of AKI were higher in the RAE group compared with the RPPP group $(46.2 \%$ vs $13.5 \%, p=0.015)$, as was distal embolism (30.8\% vs $8.1 \%, p=0.043)$. ARDS/ALI, pneumonia, sepsis or septic shock, hematoma, bacteremia, multi-organ dysfunction/MODS, infections requiring antibiotics, infections requiring surgery, local wound infections, and need for amputation were not found to be significantly different among the treatment groups (Table 2).

In total, $62 \%$ of RPPP patients and $31 \%$ of RAE patients received REBOA using a 7-Fr introducer sheath $(p=0.15)$. When examining the subgroup of patients whose maximum sheath size was $7 \mathrm{Fr}$, there were no significant differences in mortality, but AKI was higher in RAE (50\%) than in RPPP groups $(17.4 \%, p=0.015$; Table 3$)$. Distal embolism was higher in RPPP (4.3\%) than in RAE ( $0 \%)$ patients.

\section{Logistic Regression Analysis}

There were no significant differences between RAE and RPPP groups when controlling for ongoing CPR during AO initiation and duration of $\mathrm{AO}$ (Table 4). Duration of AO was also found to be significantly associated with mortality as $\mathrm{AO}$ durations of $\mathrm{AO}$ greater than $60 \mathrm{~min}$ were found to correlate with higher mortality (Table 4). Duration of AO was not found to be significantly associated with either systemic or access-related complications (Tables 5 and 6).

\section{DISCUSSION}

REBOA has been advocated in severe pelvic trauma patients to temporize fracture-related hemorrhage until definitive hemostasis can be achieved. This study focuses on a severely injured cohort as demonstrated by vital signs, ISS, and laboratory values. REBOA was initiated after a mean of $33 \mathrm{~min}$ in the resuscitation area during which time blood product resuscitation did not result in improved hemodynamic status; the mean SBP at the time of REBOA was $72 \mathrm{mmHg}$, which was not different between groups. Despite some minor differences in these protocols, based on patient characteristics, the decision to initiate REBOA was similar in all three centers. The decision to proceed to either AE or PPP was institution and resource dependent. At one institution, the trauma hybrid operating room is down the hall from the resuscitation room, immediately available, and staffed with catheter-trained trauma surgeons $[3,4]$. The concurrent 
Table 3 Outcomes and complications of 7-French final sheath diameter patients between pre-peritoneal pelvic packing only (RPPP) and angioembolization only (RAE) patients.

\begin{tabular}{lcccc}
\hline \multicolumn{1}{c}{ Outcomes } & $\begin{array}{c}\text { Total } \\
(n=27 ; 100 \%)\end{array}$ & $\begin{array}{c}\text { RPPP } \\
(n=23 ; 85.2 \%)\end{array}$ & $\begin{array}{c}\text { RAE } \\
(n=4 ; 14.8 \%)\end{array}$ & $\begin{array}{c}\text { RPP vs RAE } \\
p \text { value }\end{array}$ \\
\hline Duration of initial AO, mean \pm SD & $59.06 \pm 39.9$ & $47.86 \pm 35.1$ & $98.28 \pm 32.4$ & 0.02 \\
$\leq 60$ min, $n$ (\%) & $10(37.0)$ & $10(43.5)$ & $0(0.0)$ & $>0.05$ \\
$>60$ min, $n$ (\%) & $8(29.6)$ & $4(17.4)$ & $4(100)$ & \\
Missing, $n$ (\%) & $9(33.3)$ & $9(39.1)$ & $0(0.0)$ & \\
In hospital mortality, $n$ (\%) & $3(11.1)$ & $2(8.7)$ & $1(25.0)$ & 0.470 \\
Complications $\geq 1, n,(\%)$ & $12(44.4)$ & $10(43.5)$ & $2(50.0)$ & 0.809 \\
Acute kidney injury, $n$ (\%) & $6(22.2)$ & $4(17.4)$ & $2(50.0)$ & 0.015 \\
ALI or ARDS, $n$ (\%) & $4(14.8)$ & $4(17.4)$ & $1(25.0)$ & 0.662 \\
Distal embolism, $n$ (\%) & $1(3.7)$ & $1(4.3)$ & $0(0.0)$ & 0.043 \\
Pneumonia, $n$ (\%) & $4(14.8)$ & $4(17.4)$ & $0(0.0)$ & 0.944 \\
Sepsis or septic shock, $n$ (\%) & $1(3.7)$ & $1(4.3)$ & $0(0.0)$ & 0.452 \\
Hematoma, $n$ (\%) & $1(3.7)$ & $1(4.3)$ & $0(0.0)$ & 0.098 \\
Bacteremia, $n$ (\%) & $1(3.7)$ & $1(4.3)$ & $0(0.0)$ & 0.43 \\
Multi-organ dysfunction/MODS, $n(\%)$ & $0(0.0)$ & $0(0.0)$ & $0(0.0)$ & 0.549 \\
Infection requiring antibiotics, $n(\%)$ & $1(3.7)$ & $1(4.3)$ & $0(0.0)$ & 0.549 \\
Infection requiring surgery, $n(\%)$ & $1(3.7)$ & $1(4.3)$ & $0(0.0)$ & 0.549 \\
Local wound infection, $n$ (\%) & $1(3.7)$ & $1(4.3)$ & $0(0.0)$ & 0.549 \\
Need for amputation, $n$ (\%) & $0(0.0)$ & $0(0.0)$ & $0(0.0)$ & 0.549 \\
\hline
\end{tabular}

Table 4 Binomial logistic regression examining the outcome of mortality between pre-peritoneal pelvic packing only (RPPP) and angioembolization only (RAE) patients when controlling for CPR during $\mathrm{AO}$ and duration of $\mathrm{AO}$.

\begin{tabular}{lcc}
\hline Independent covariates & \multicolumn{1}{c}{ Mortality } & $\begin{array}{c}\text { Mortality excluding } \\
\text { patients with CPR at AO } \\
\text { OR }(95 \% \mathrm{Cl})\end{array}$ \\
\hline RAE vs RPPP & $0.146(0.004,5.119)$ & $2.52(0.062,102.06)$ \\
CPR during AO & $649.5(1.697,24853)^{*}$ & $\mathrm{~N} / \mathrm{A}$ \\
AO duration & $1.073(1.01,1.14)^{*}$ & $1.062(1.004,1.124)^{*}$ \\
\hline
\end{tabular}

*Denotes $p<0.05$. Cl: confidence interval; OR: operating room.

Table 5 Binomial logistic regression examining the outcome of mortality between pre-peritoneal pelvic packing only (RPPP) and angioembolization only (RAE) patients when controlling for SBP pre-AO and duration of AO.

\begin{tabular}{lcc}
\hline Independent covariates & Mortality & Complications $\geq 1$ \\
& OR $(95 \% \mathrm{Cl})$ & OR $(95 \% \mathrm{Cl})$ \\
\hline RAE vs RPPP & $2.284(0.138,37.704)$ & $12.585(0.939,168)$ \\
SBP pre-AO & $0.909(0.787,1.048)$ & $0.949(0.889,1.012)$ \\
AO duration & $1.047(1.003,1.094)^{*}$ & $0.992(0.965,1.019)$ \\
\hline
\end{tabular}

${ }^{*}$ Denotes $p<0.05$.

implementation of REBOA, a trauma hybrid room, and trauma surgeons with endovascular training has led to a near-abandonment of PPP. A second institution has interventional radiologists immediately available who are paged upon admission of any patient with a severe pelvic fracture who receives a REBOA. Almost all patients in the RAE group were enrolled from these two sites. The third institution has immediate access to trauma operating rooms, interventionalists who are available when consulted, and has set the gold standard for preperitoneal packing in trauma [5]. A retrospective study from this site investigating 40 patients with hemodynamic 
Table 6 Binomial logistic regression examining the outcomes of mortality and complications within Zone 3 patients with 7-French final catheter diameter between pre-peritoneal pelvic packing only (RPPP) and angioembolization only (RAE) patients when controlling for SBP pre-AO and duration of AO.

\begin{tabular}{|c|c|c|}
\hline Independent Covariates & $\begin{array}{c}\text { Mortality } \\
\text { OR }(95 \% \text { CI) }\end{array}$ & $\begin{array}{c}\text { Complications } \geq 1 \\
\text { OR }(95 \% \mathrm{Cl})\end{array}$ \\
\hline RAE vs RPPP & $0.166(0,110.03)$ & $2.514(0.101,62.62)$ \\
\hline SBP pre-AO & $0.974(0.844,1.125)$ & $0.929(0.840,1.027)$ \\
\hline AO duration & $1.06(0.978,1.149)$ & $1.000(0.970,1.031)$ \\
\hline
\end{tabular}

instability from pelvic hemorrhage demonstrated that PPP decreases need for pelvic AE and post-procedure blood transfusions [6], although this was performed prior to the advent of REBOA. Almost all patients in the RPPP group were enrolled from the third site.

There is little data available to recommend safe duration of $\mathrm{AO}$ in Zone 3. In this study, $\mathrm{AO}$ for longer than $60 \mathrm{~min}$ resulted in higher mortality. These findings are consistent with guidelines for clinical use of REBOA lead by the Committee on Trauma, which recommend a target duration of $\mathrm{AO}$ for $30 \mathrm{~min}$ at Zone 3, with a maximum of $60 \mathrm{~min}$ [7]. While it was not captured, the use of partial or intermittent $\mathrm{AO}$ was not routinely used at any of the institutions during this time period.

If the duration of $\mathrm{AO}$ is used as a surrogate for time to hemostasis, it appears that hemostasis can occur fastest with PPP, most likely due to the immediate availability of an operating room and surgeon to perform it. The longer duration of AO in the RAE group may be related to one institution's initial learning curve with $\mathrm{AE}$ and hybrid room workflow, or due to the availability of consultants, physical space, and location at others. Recent evidence demonstrates that a surgical endovascular service can result in faster times to hemostasis compared with IR-based teams [2], but no comparisons have been made between PPP and AE.

Mortality was unaffected by method of hemostasis after REBOA, including in those patients who required both PPP and AE for definitive hemostasis. Location of death was significant, however, with all deaths in the RAE and RPPPAE group occurring in the ICU whereas $75 \%$ of the deaths in the RPPP group occurred in the $\mathrm{OR}$. This finding is not consistent with the duration of $\mathrm{AO}$, as the RPPP patients had shorter durations of AO, thus location of death must be due to other factors not captured in this study. More RPPP survivors were discharged home compared with those who survived to discharge after RAE; the reason for this difference in hospital disposition is also unclear.

AKI rates were high in both RAE and RPPPAE groups, and significantly higher in the RAE group than the RPPP group, despite the RAE group receiving significantly more crystalloid. Rates of AKI in a multi-institutional trial of REBOA patients have been reported up to $18 \%$ [8] and are likely due to the systemic inflammatory response to $\mathrm{AO}$ as well as the initial injury and resultant hypoperfusion to the kidneys prior to AO. Despite the fact that $\mathrm{AO}$ occurred below the levels of the renal arteries allowing "normal" antegrade renal blood flow, patients still had significant AKI. The renin-angiotensin-aldosterone system responds to hypoperfusion at any level by increasing angiotensin II, which increases renal vascular resistance and results in decreased renal function. This mechanism may explain why AKI is high in REBOA patients as they are in profound hemorrhagic shock. Rates of AKI in patients in hemorrhagic shock who did not receive REBOA have been reported to be higher than the patients in the RPPP group, particularly those with a longer time to hemostasis [9]. The AKI is more likely to due to initial hypoperfusion than AO. The higher rate of AKI in the RAE group could be multi-factorial: patients were exposed to nephrotoxic contrast for the AE procedures and the duration of $\mathrm{AO}$ was longer, which likely increased the systemic inflammatory response to AO. As with time to hemostasis, the volume of contrast utilized may have been greater as this time period represented the onset of the AE learning curve in one institution.

The second most common systemic complication was ALI/ARDS, which was slightly higher than rates previously reported for REBOA patients [10], but not different between groups. The high rates of pulmonary complications suggest that the systemic inflammatory response to $\mathrm{AO}$ is profound, and further research is needed to identify clinical strategies to protect pulmonary function during and after $\mathrm{AO}$ and subsequent procedures for hemostasis.

Most patients received REBOA with a 7-Fr sheath, and among those patients the most common access-related complication was distal embolism, which was significantly higher in the RPPP group. It is unknown whether this could be due to mechanical compression on the inflow to the common femoral artery and pelvic outflow by PPP or other factors. A recent multi-institutional trial comparing access complications demonstrated that the rates of distal embolism have significantly decreased with the use of smaller introducer sheaths [8], and this is likely to continue 
to improve with advances in technology that will provide lower profile devices in the future.

Several limitations exist in this study. The number of patients in each group was relatively low, which can result in type II errors for all variables. Several variables were not recorded in some institutions, such as in-dwelling sheath time and time to hemostasis, which can provide valuable information. Lastly, the three institutions were performing REBOA and resultant procedures based on their available resources. This observational study was designed primarily to address how REBOA may be used as an adjunct to hemorrhage control in different hospital settings with different resources.

\section{CONCLUSION}

Despite a longer duration of $\mathrm{AO}$ and higher rates of ongoing CPR at the time of AO in RAE patients, mortality rates are similar whether hemostasis is achieved after REBOA with PPP or AE. Using contemporary devices for REBOA, RPPP results in higher rates of AKI with $\mathrm{AE}$, and higher rates of distal embolism with PPP. These complications appear to be independent of the duration of $\mathrm{AO}$, physiology at the time of $\mathrm{AO}$, use of transexamic acid, and blood products transfused. In-dwelling sheath times and/or time to definitive hemostasis may play a role in these findings; however, further study is required. Clinical strategies to protect renal and pulmonary function are required in order to maximize systemic insults from hemorrhagic shock and AO.

\section{Ethics Statement}

(1) All the authors mentioned in the manuscript have agreed to authorship, read and approved the manuscript, and given consent for submission and subsequent publication of the manuscript.

(2) The authors declare that they have read and abided by the JEVTM statement of ethical standards including rules of informed consent and ethical committee approval as stated in the article.

\section{Conflicts of Interest}

Megan Brenner and Charles Fox are Prytime Medical Inc. Clinical Advisory Board members. The remaining authors have no conflicts of interest .

\section{Funding}

A portion of this study was funded by a clinical grant from the Department of Defense no. W81XWH-15-1-0025.

\section{Author Contributions}

$\mathrm{MB}$ carried out the literature search. $\mathrm{MB}, \mathrm{AR}$, and $\mathrm{CCB}$ were responsible for the study design. MB, LM, BZ, AS,
AC, AR, CF, TS, and CCB were responsible for data collection. $\mathrm{MB}, \mathrm{LM}$, and $\mathrm{BZ}$ carried out data analysis. $\mathrm{MB}$. LM, BZ, AS, AC, CF, TS, and CCB were responsible for data interpretation. $\mathrm{MB}, \mathrm{BZ}$, and $\mathrm{CCB}$ were responsible for the writing. MB, LM, CF, TS, and CCB carried out the critical revision.

\section{REFERENCES}

[1] Tran TLN, Brasel KJ, Karmy-Jones R, et al. Western Trauma Association critical decisions in trauma: management of pelvic fracture with hemodynamic instability2016 updates. J Trauma Acute Care Surg. 2006;81(6): 1171-4.

[2] Coccolini F, Stahel PF, Montori G, et al. Pelvic trauma: WSES classification and guidelines. World J Emerg Surg. 2017;12:5.

[3] Brenner M, Hoehn M, Teeter W, Stein D, Scalea T. Trading scalpels for sheaths: catheter-based treatment of vascular injury can be effectively performed by acute care surgeons trained in endovascular techniques. J Trauma Acute Care Surg. 2016;80(5):783-6.

[4] Morrison JJ, Dubose JJ, Brenner M, Scalea T. A surgical endovascular trauma service increases case volume and decreases time to hemostasis. Ann Surg. 2019; 270(4):612-19.

[5] Burlew CC, Moore EE, Stahel PF, et al. Preperitoneal pelvic packing reduces mortality in patients with life-threatening hemorrhage due to unstable pelvic fractures. J Trauma Acute Care Surg. 2017;82(2):233-42.

[6] Osborn PM, Smith WR, Moore EE, et al. Direct retroperitoneal pelvic packing versus pelvic angiography: a comparison of two management protocols for haemodynamically unstable pelvic fractures. Injury. 2009;40(1): 54-60.

[7] Bulger EM, Perina DG, Qasim Z, et al. Clinical use of resuscitative endovascular balloon occlusion of the aorta (REBOA) in civilian trauma systems in the USA, 2019: a joint statement from the American College of Surgeons Committee on Trauma, the American College of Emergency Physicians, the National Association of Emergency Medical Services Physicians and the National Association of Emergency Medical Technicians. Trauma Surg Acute Care Open. 2019;4(1): e000376.

[8] DuBose JJ, Morrison J, Brenner M, et al. Comparison of 7 and 11-12 French access for REBOA: results from the AAST Aortic Occlusion for Resuscitation in Trauma and Acute Care Surgery (AORTA) registry. J Endovasc Resusc Trauma Manag. 2019;3(1):15-21.

[9] Chang R, Kerby JD, Kalkwarf KJ, et al. Earlier time to hemostasis is associated with decreased mortality and rate of complications: results from the Pragmatic Randomized Optimal Platelet and Plasma Ratio trial. J Trauma Acute Care Surg. 2019;87(2):342-9.

[10] DuBose JJ, Scalea TM, Brenner M, et al. The AAST prospective Aortic Occlusion for Resuscitation in Trauma and Acute Care Surgery (AORTA) registry: data on contemporary utilization and outcomes of aortic occlusion and resuscitative balloon occlusion of the aorta (REBOA). J Trauma Acute Care Surg. 2016;81(3):409-19. 